\title{
A COMMON FIXED POINT THEOREM FOR TWO SEQUENCES OF SELF-MAPPINGS
}

\author{
TAKESHI TANIGUCHI \\ Department of Mathematics \\ Kerume University \\ Miimachi, Kurume, Fukuoka, Japan \\ (Received September 7, 1988 and in revised form April 19, 1989)
}

\begin{abstract}
In this paper a common fixed point theorem for two sequences of self-mappings from a complete metric space $M$ to $M$ is proved. Our theorem is a generalization of Hadzic's fixed point theorem[1].
\end{abstract}

KEY WORDS AND PHRASES. A common fixed point, self-mappings and complete metric spaces.

1980 AMS(MOS) SUBJECT CLASSIFICATION CODES. 47H10.

\section{INTRODUCTION.}

Banach's fixed point theorem has been generalized by many authors. Among such investigations there are several, interesting and important studies[2]. Particularly, K. Iseki[3] proved a fixed point theorem of a sequence of self-mappings from a complete metric space $M$ to $M$. We are interested in fixed point theorems of a sequence of self-mappings since they pertain to the problem of finding an equilibrium point of a difference equation $x_{n+1}=f\left(n, x_{n}\right) \quad(n=1,2, \ldots)$.

Recently $O$. Hadzic proved the existence of a common fixed point for the sequence of selfmappings $\left\{A_{j}\right\}(j=1,2, \ldots), \mathrm{S}$ and $\mathrm{T}$ where $A$, commutes with $\mathrm{S}$ and $\mathrm{T}$. His result is as follows:

THEOREM 1. Let $(\mathrm{M}, \mathrm{d})$ be a complete metric space, $\mathrm{S}, \mathrm{T}: \mathrm{M} \rightarrow \mathrm{M}$ be continuous, $A_{j}: M \rightarrow S M \cap T M(j=1,2, \ldots)$ so that $A_{j}$ commutes with $\mathrm{S}$ and $\mathrm{T}$ and for every $i, j(i==j, i, j=1,2, \ldots)$ and every $x, y \in M$ :

$$
d\left(A_{\imath} x, A, y\right) \leq q d(S x, T y), \quad 0<q<1
$$

Using Theorem 1, he gave a generalization of Gohde's fixed point theorem and extended Krasnoseliski's fixed point theorem.

In this paper we shall present a generalization of Hadzic's fixed point theorem. 
2. MAIN THEOREMS.

Let $\mathrm{N}$ denote the set of all positive integers. In this section we shall prove the following theorem.

THEOREM A. Let (M,d) be a complete metric space and let $\left\{A_{p}\right\},\left\{B_{q}\right\}(p, q=1,2, \ldots)$, be two sequences of mappings from $M$ to $M$.

Suppose that the following conditions are satisfied; for all $m, n \in N$ and all $x, y \in M$,

(a) there exists a constant $\mathrm{k}(0<k<1)$ such that

$$
\begin{gathered}
d\left(A_{2 n-1} x, A_{2 n} y\right) \leq k d\left(B_{2 n-1} x, B_{2 n} y\right), \\
d\left(A_{2 n} x, A_{2 m+1} y\right) \leq k d\left(B_{2 n} x, B_{2 m+1} y\right), \text { for all } m \geq n \geq 1,
\end{gathered}
$$

(b) $A_{2 n} B_{2 m}=B_{2 m} A_{2 n}$ and $A_{2 n-1} B_{2 m-1}=B_{2 m-1} A_{2 n-1}$,

(c) $B_{2 n} B_{2 m}=B_{2 m} B_{2 n}$ and $B_{2 m-1} B_{2 n-1}=B_{2 n-1} B_{2 m-1}$,

(d) $A_{2 n-1}(M) \subset B_{2 n}(M)$ and $A_{2 n}(M) \subset B_{2 n+1}(M)$.

If each $B_{q}(q=1,2, \ldots)$ is continuous, then there exists a unique fixed point for two sequences $\left\{A_{p}\right\}$ and $\left\{B_{q}\right\}(p, q=1,2, \ldots)$.

PROOF. Let $x_{0}$ be an arbitrary point in M. By condition (d) there exists a point $x_{1} \in M$ such that $A_{1} x_{0}=B_{2} x_{1}$. Next we choose a point $x_{2} \in M$ such that $A_{2} x_{1}=B_{3} x_{2}$. Inductively, we can define by condition $(d)$, the sequence $\left\{x_{n}\right\}$ such that

$$
A_{2 n-1} x_{2 n-2}=B_{2 n} x_{2 n-1} \text { and } A_{2 n} x_{2 n-1}=B_{2 n+1} x_{2 n}, \quad n \in N .
$$

First of all we shall show that $\left\{B_{n} x_{n-1}\right\}$ is a Cauchy sequence. By (2.1) and condition (a), we obtain that for all $n \in N$

$$
\begin{aligned}
& d\left(B_{2 n-1} x_{2 n-2}, B_{2 n} x_{2 n-1}\right)=d\left(A_{2 n-2^{x}} x_{2 n-3}, A_{2 n-1} x_{2 n-2}\right) \\
\leq & k d\left(B_{2 n-2^{2 n-3}}, B_{2 n-1} x_{2 n-2}\right)=k d\left(A_{2 n-3} x_{2 n-4}, A_{2 n-2^{2 n-3}}\right) \\
\leq & k^{2} d\left(B_{2 n-3} x_{2 n-4}, B_{2 n-2^{2 n-3}}\right) \leq \ldots . . k^{2 n-2} d\left(B_{1} x_{0}, B_{2} x_{1}\right)
\end{aligned}
$$

and similarly that

$$
\begin{aligned}
& d\left(B_{2 n} x_{2 n-1}, B_{2 n+1} x_{2 n}\right)=d\left(A_{2 n-1} x_{2 n-2}, A_{2 n} x_{2 n-1}\right) \\
\leq & k d\left(B_{2 n-1} x_{2 n-2}, B_{2 n} x_{2 n-1}\right) \leq \ldots . . \leq k^{2 n-1} d\left(B_{1} x_{0}, B_{2} x_{1}\right) .
\end{aligned}
$$


Since $0<k<1$, this implies that the sequence $\left\{B_{n} x_{n-1}\right\}$ is a Cauchy sequence. Thus $\left\{B_{n} x_{n-1}\right\}$ converges to some point $\mathrm{v}$ in $\mathrm{M}$ because $\mathrm{M}$ is complete. Now since each $B_{q}(q \in N)$ is continuous, we obtain that

$$
\begin{gathered}
B_{2 m} v=B_{2 m}\left(\lim _{n \rightarrow \infty} B_{2 n+1} x_{2 n}\right)=\lim _{n \rightarrow \infty}\left(B_{2 m} B_{2 n+1} x_{2 n}\right) \\
=\lim _{n \rightarrow \infty}\left(B_{2 m} A_{2 n} x_{2 n-1}\right)=\lim _{n \rightarrow \infty}\left(A_{2 n} B_{2 m} x_{2 n-1}\right)
\end{gathered}
$$

and similarly that $B_{2 m+1} v=\lim _{n \rightarrow \infty}\left(A_{2 n+1} B_{2 m+1} x_{2 n}\right)$ and $B_{2 m-1} v=\lim _{n \rightarrow \infty}\left(A_{2 n-1} B_{2 m-1} x_{2 n-2}\right)$. Hence by condition (c), we have

$$
\begin{aligned}
d\left(B_{2 m} v, B_{2 m+1} v\right) & =\lim _{n \rightarrow \infty} \mathrm{d}\left(A_{2 n} B_{2 m} x_{2 n-1}, A_{2 n+1} B_{2 m+1} x_{2 n}\right) \\
& \leq \lim _{n \rightarrow \infty} \mathrm{kd}\left(B_{2 n} B_{2 m} x_{2 n-1}, B_{2 n+1} B_{2 m+1} x_{2 n}\right) \\
& =k d\left(B_{2 m} v, B_{2 m+1} v\right)
\end{aligned}
$$

and $d\left(B_{2 m} v, B_{2 m-1} v\right) \leq k d\left(B_{2 m} v, B_{2 m-1} v\right)(m \in N)$ in like manner, which implies that $B_{m} v=B_{m+1} v$ for all $m \geq 1$. Next we shall show that $A_{n} v=B_{n} v$ for all $n \leq 1$. By (2.1), conditions (b) and (c), we have

$$
\begin{aligned}
d\left(B_{2 n+1} B_{2 m+{ }^{2}} x_{2 m+1}, A_{2 n} v\right) & =d\left(A_{2 m+1} B_{2 n+1} x_{2 m}, A_{2 n} v\right) \\
& \leq k d\left(B_{2 m+1} B_{2 n+1} x_{2 m}, B_{2 n} v\right) \\
& =k d\left(B_{2 n+1} B_{2 m+1} x_{2 m}, B_{2 n} v\right)
\end{aligned}
$$

Thus letting $m \rightarrow \infty$, we obtain that $d\left(B_{2 n+1} v, A_{2 n} v\right) \leq k d\left(B_{2 n+1} v, B_{2 n} v\right)$ from which it follows that $A_{2 n} v=B_{2 n+1} v$ for all $n \geq 1$. And since

$$
d\left(A_{2 n-1} v, A_{2 n} v\right) \leq k d\left(B_{2 n-1} v, B_{2 n} v\right) \text { and } d\left(A_{2 n+1} v, A_{2 n} v\right) \leq k d\left(B_{2 n+1} v, B_{2 n} v\right),
$$

we obtain that $A_{n} v=A_{n+1} v=B_{n+1} v=B_{n} v$ for all $n \in N$. Furthermore, for all $n \in N$, we obtain

$$
\begin{gathered}
d\left(A_{2 n} v, A_{2 n-1} A_{2 n+1} v\right) \leq k d\left(B_{2 n} v, B_{2 n-1} A_{2 n+1} v\right)=k d\left(A_{2 n} v, A_{2 n-1} A_{2 n+1} v\right) \\
\text { and } d\left(A_{2 n-1} v, A_{2 n} A_{2 n+1} v\right) \leq k d\left(B_{2 n-1} v, B_{2 n} A_{2 n+1} v\right)=k d\left(A_{2 n-1} v, A_{2 n} A_{2 n+1} v\right) .
\end{gathered}
$$

Therefore we obtain $u=A_{p}(u)=B_{p}(u)$ for all $p \geq 1$ setting $u=A_{n} v$ because $0<k<1$. 
Now we shall prove that $\mathrm{u}$ is a unique common fixed point of $\left\{A_{p}\right\}$ and $\left\{B_{p}\right\}$. If there exists another point $\mathrm{w}$ such that $w=A_{p} w=B_{p} w$ for all $p>1$, then

$$
\begin{gathered}
d(u, w)=d\left(A_{2 m-1} u, A_{2 m} w\right) \leq k d\left(B_{2 m-1} u, B_{2 m} w\right) \\
\leq k d(u, w)
\end{gathered}
$$

which is a contradiction since $0<k<1$. Therefore $\mathrm{u}$ is a unique common fixed point of two sequences of self-mappings $\left\{A_{n}\right\}$ and $\left\{B_{n}\right\}$. This completes the proof.

If $S=B_{2 n-1}$ and $T=B_{2 n}(n=1,2, \ldots)$, we obtain Theorem 1 as the corollary of Theorem A. Next we obtain the following theorem which is a generalization of Theorem 1 in [4].

THEOREM B. Let $(M, d)$ be a complete metric space and let $\left\{T_{p}\right\}(p=1,2, \ldots)$ be a sequence of mappings from $M$ to $M$. Suppose that the following conditions as satisfied for all $m \geq n \geq 1$ and $x, y \in M$

(e) there exists a constant h $(h>1)$ such that

$$
d\left(T_{2 n-1} x, T_{2 n} y\right) \geq h d(x, y) \text { and } \mathrm{d}\left(T_{2 n} x, T_{2 m+1} y\right) \geq h d(x, y),
$$

(f) $T_{p} T_{q}=T_{q} T_{p} \quad(\mathrm{p}, \mathrm{q}$ are even or odd respectively).

If every $T_{n}$ is continuous on $M$ and $T_{n}(M)=M(n=1,2, \ldots)$, then there exists a unique fixed point for $T_{n}$.

PROOF. Set $A_{n}=\mathrm{I}$ ( $\mathrm{I}$ is the identify map from $\mathrm{M}$ to $\mathrm{M}$ ) in Theorem A. The proof is complete.

REMARK 1. We remark that the mapping $f: X \rightarrow X$ in Theorem 1 of [4] is continuous from the condition of the theorem.

\section{REFERENCES}

1. HADZIC, O. Common Fixed Point Theorems for Family of Mappings in Complete Metric Spaces, Math.Japan. 29 (1984), 127-134.

2. JOSHI, M.C. and BOSE, R.K., Some Topics in Nonlinear Functional Analysis, John Wiley and Sons, New York, 1985.

3. ISEKI, K. On Common Fixed Points of Mappings, Bull.Austr.Math.Soc. 10(1975), 365-370.

4. WANG, S.Z., LI, B.Y., GAO, Z.M., and ISEKI, K. Some Fixed Point Theorems on Expansion Mappings, Math.Japan. 29(1984), 631-636.

5. CIRIC, B. A Generalization of Banach's Contraction Principle, Proc. Amer. Math. Soc. $4 \underline{45}$ (1974), 267-237.

6. GILlESPIE, A.A. and WILlIAMS, B.B. Fixed Point Theorems for Expanding Maps, Applicable Analysis, 14 (1984), 161-165.

7. JUNGCK, G. Commuting Mappings and Fixed Points, Amer.Math.Monthly $83(1976), 261-$ 263.

8. RHOADES, B.E., Contractive Definitions Revisited, Topological Methods in Nonlinear Functional Analysis, Contemp. Math. Amer. Math. Soc. 21(1983), 190-205. 


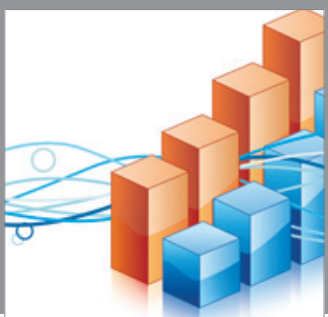

Advances in

Operations Research

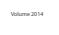

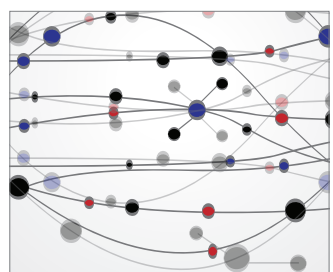

\section{The Scientific} World Journal
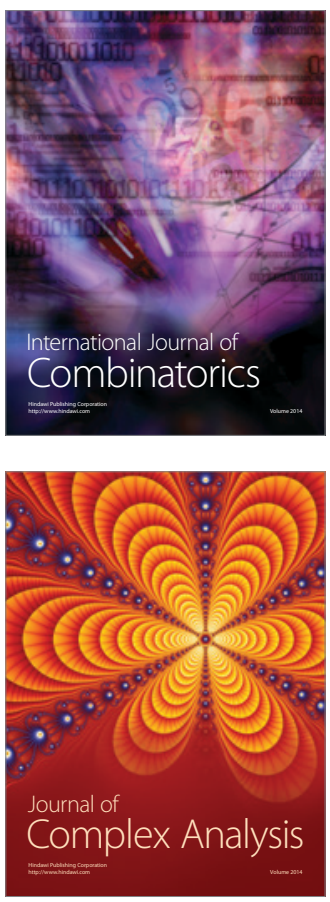

International Journal of

Mathematics and

Mathematical

Sciences
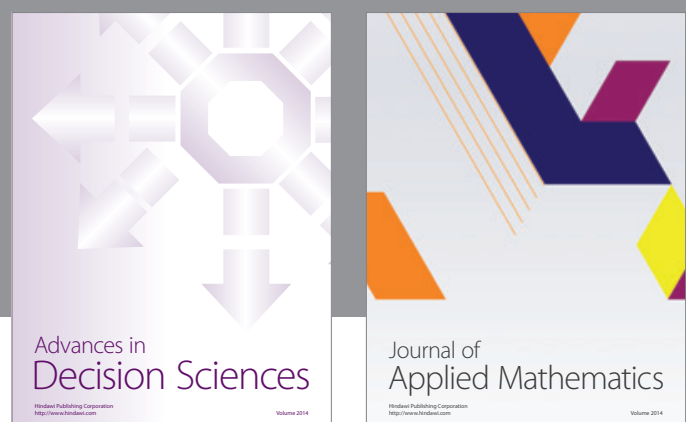

Journal of

Applied Mathematics
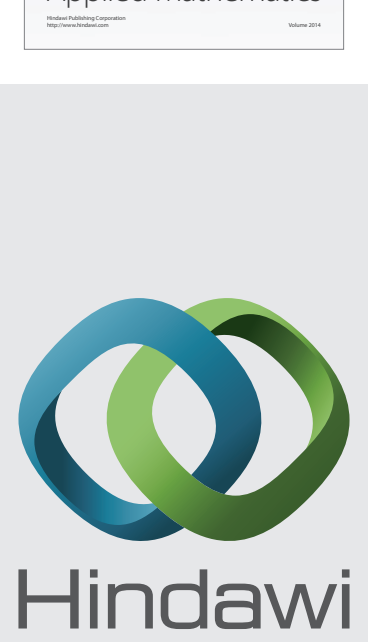

Submit your manuscripts at http://www.hindawi.com
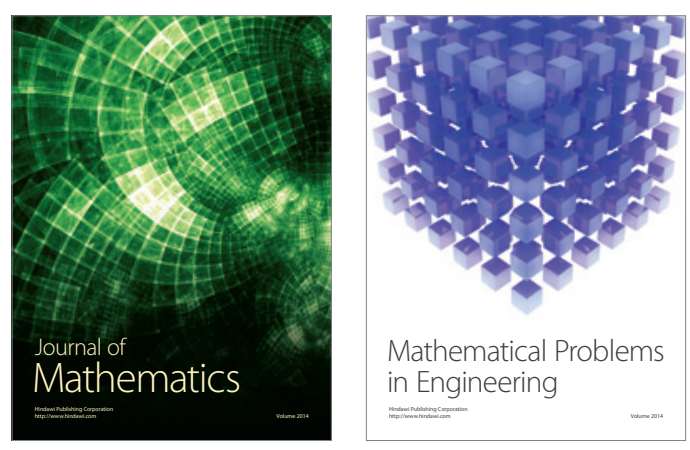

Mathematical Problems in Engineering
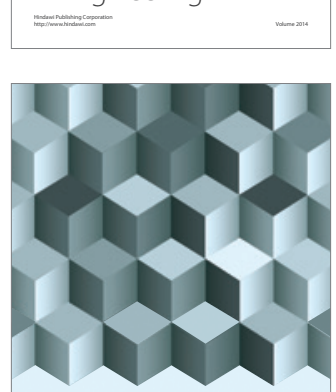

Journal of

Function Spaces
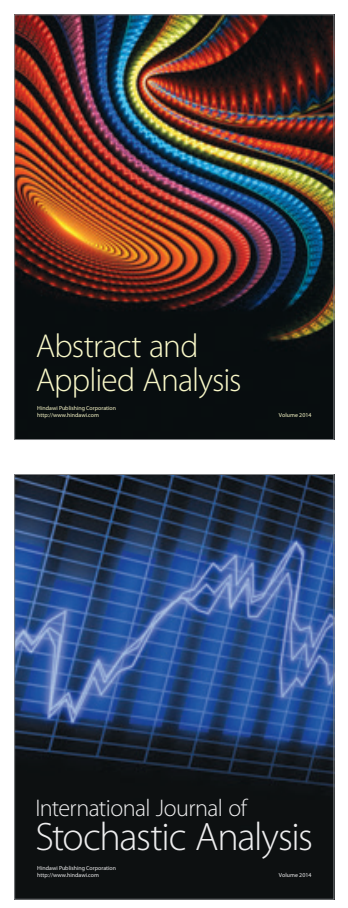

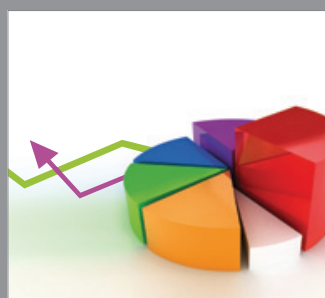

ournal of

Probability and Statistics

Promensencen
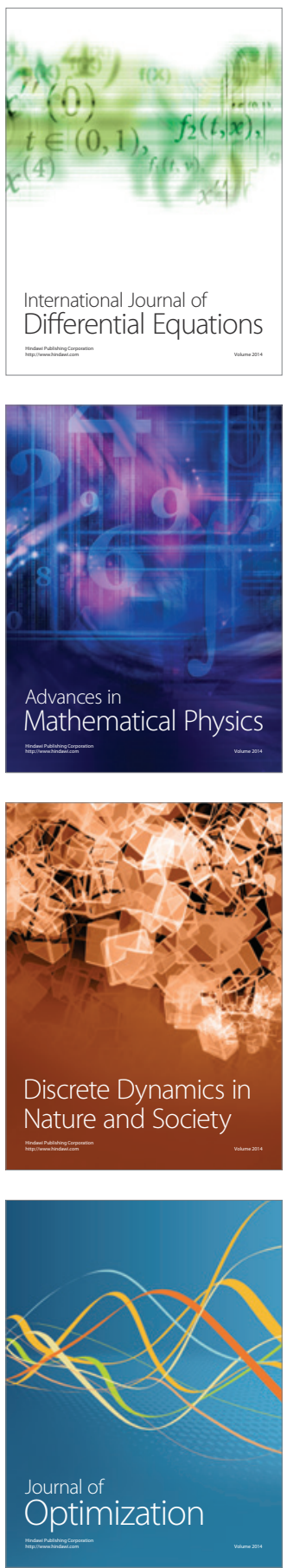